\title{
Simultaneous two-photon activation of presynaptic cells and calcium imaging in postsynaptic dendritic spines
}

\author{
Masanori Matsuzaki ${ }^{1,2,34^{*}}$, Graham CR Ellis-Davies ${ }^{5}$, Yuya Kanemoto ${ }^{1,2}$, Haruo Kasai ${ }^{1,2}$
}

\begin{abstract}
Background: Dendritic spines of pyramidal neurons are distributed along the complicated structure of the dendritic branches and possess a variety of morphologies associated with synaptic strength. The location and structure of dendritic spines determine the extent of synaptic input integration in the postsynaptic neuron. However, how spine location or size relates to the position of innervating presynaptic cells is not yet known. This report describes a new method that represents a first step toward addressing this issue.

Results: The technique combines two-photon uncaging of glutamate over a broad area ( 500 $\times 250 \times 100 \mu \mathrm{m})$ with two-photon calcium imaging in a narrow region $(\sim 50 \times 10 \times 1 \mu \mathrm{m})$. The former was used for systematic activation of layer $2 / 3$ pyramidal cells in the rat motor cortex, while the latter was used to detect the dendritic spines of layer 5 pyramidal cells that were innervated by some of the photoactivated cells. This technique allowed identification of various sizes of innervated spine located $<140 \mu \mathrm{m}$ laterally from the postsynaptic soma. Spines distal to their parent soma were preferentially innervated by cells on the ipsilateral side. No cluster of neurons innervating the same dendritic branch was detected.
\end{abstract}

Conclusions: This new method will be a powerful tool for clarifying the microarchitecture of synaptic connections, including the positional and structural characteristics of dendritic spines along the dendrites.

\section{Background}

The microarchitecture of synaptic connections determines information processing in cortical circuits. The inter/intra-layer and inter/intra-columnar architecture of synaptic connectivity has been revealed by laser-scanning one- or two-photon stimulation of neurons with caged glutamate [1-7]. Although previous experiments have measured the amplitude of postsynaptic currents or depolarization, they have not been able to identify the sites of synaptic connections.

The structure and location of dendritic spines, the major postsynaptic sites of excitatory synapses, are crucial to information integration in the postsynaptic cell [8]. Spine size correlates well with the number of functional $\alpha$-amino-3-hydroxy-5-methyl-4-isoxazolepropionic

\footnotetext{
* Correspondence: mzakim@nibb.ac.jp

'Laboratory of Structural Physiology, Center for Disease Biology and Integrative Medicine, Graduate School of Medicine, University of Tokyo, Tokyo, Japan

Full list of author information is available at the end of the article
}

(AMPA) receptors [9-11]. Dendritic spine location determines the extent to which depolarization spreads into the soma, the local dendritic spike, and synaptic plasticity [12,13]. Induction of nonlinear depolarization had been suggested to require the activation of dozens of dendritic spines along the same dendritic tree within a narrow time window ( $\sim 6 \mathrm{~ms})[14,15]$. Functionally or spatially associated pyramidal cells innervating the same dendritic branch of a postsynaptic cell may cause correlated activation in the brain. In order to examine this possibility, the location of presynaptic cells and the size and location of the dendritic spines that they innervate must be determined.

Although it is possible to determine the structure and location of synaptic connectivity by staining pairrecorded cells, it is very difficult to identify pairs of connecting cells over a relatively broad area and then find their synaptic sites [16-19]. In this study, we developed a new method that combines calcium $\left(\mathrm{Ca}^{2+}\right)$ imaging with photostimulation via two-photon macro photolysis
C Biomed Central

() 2011 Matsuzaki et al; licensee BioMed Central Ltd. This is an Open Access article distributed under the terms of the Creative Commons Attribution License (http://creativecommons.org/licenses/by/2.0), which permits unrestricted use, distribution, and reproduction in any medium, provided the original work is properly cited. 
of caged glutamate (2pMAPG) [7]. The volume of uncaged glutamate is restricted to the focal volume of the laser beam. Thus, it is possible to map the approximate positions of photostimulated cells that induce postsynaptic currents in a patch-clamped cell via threedimensional (3D) scanning of laser focal volumes from 2pMAPG in slices of rat cortex [7]. During 2pMAPG mapping in layer $2 / 3$, we also performed $\mathrm{Ca}^{2+}$ imaging in the dendrites of layer 5 pyramidal cells and identified dendritic spines in which photostimulated cells triggered 2pMAPG-mediated $\mathrm{Ca}^{2+}$ transients. We found that spines located distal to their parent soma were innervated preferentially by cells on the ipsilateral side.

\section{Results}

\section{Activation of layer $2 / 3$ pyramidal cells with 2 pMAPG mapping}

First, the 3D 2pMAPG mapping of induced action potentials (APs) was validated in layer $2 / 3$ pyramidal cells in the rat motor cortex. In order to activate a large number of glutamate receptors to induce APs, the focal volume for 2pMAPG was expanded with a 720-nm laser beam [7]. The point-spread function of the focal volume for $2 \mathrm{pMAPG}$ was estimated using $0.1-\mu \mathrm{m}$ fluorescent beads at lateral and axial full-width at half-maximum values (FWHMs) of $1.03 \pm 0.04 \mu \mathrm{m}$ and $15.4 \pm 0.7 \mu \mathrm{m}$ $(n=11)$, respectively. These lateral and axial FWHMs were 3.8- and 9.8-fold longer, respectively, than those for two-photon imaging using the $830-\mathrm{nm}$ laser beam (see Methods). Therefore, the 2pMAPG volume was approximately 140 -fold larger $(3.8 \times 3.8 \times 9.8)$ than that obtained by two-photon imaging.

Whole-cell patch clamp recordings were performed on layer $2 / 3$ pyramidal cells from the motor cortex using acute slices, which were perfused with extracellular solution containing caged glutamate (4-carboxymethoxy-5,7dinitroindolinyl-glutamate, CDNI-glutamate) [20]. The structure of each recorded cell was visualized by loading Alexa Fluor 594 from the whole-cell pipette (Figure 1A) and 2 pMAPG was performed at each of $16 \times 8$ pixels (spacing, $31 \mu \mathrm{m}$ ) within a region of $500 \times 250 \mu \mathrm{m}$ in a single plane. Mapping was carried out at three depths from the slice surface at intervals of $50 \mu \mathrm{m}$, so that 2 pMAPG occurred at $128 \times 3=384$ points within the $3 \mathrm{D}$ area of each recorded cell. The soma of the recorded cell was near the centre of this $3 \mathrm{D}$ mapping area. At sites in the perisomatic and proximal dendritic region, 2pMAPG could induce APs, as previously described (Figure $1 \mathrm{~B}$ and $1 \mathrm{C}$ ) [7]. This region was supposed to have a larger membrane area included within and/or near the focal spot than that of a thin distal dendritic branch. This difference may cause the total number of activated glutamate receptors to be larger in the former membrane than in the latter, although spine density is lower in the perisomatic area than in the dendritic branch [21]. The observed tendency of perisomatic 2pMAPG to frequently induce APs was similar to that in the case of ultraviolet photostimulation [5]. The number of AP-evoking pixels was $7.9 \pm 0.7$ per cell (range 5$11, n=8$ cells), and the number of APs per AP-evoking pixel was $1.8 \pm 0.1$ (range $1-4, n=63$ pixels). No AP was induced more than $120 \mathrm{~ms}$ after the onset of 2pMAPG.

We examined whether the $3 \mathrm{D}$ center of the stimulated cell soma could be predicted from the positions of APevoking pixels. Comparison of the center of the soma and the average position of the AP-evoking pixels indicated only slight positional differences $(-12 \pm 12 \mu \mathrm{m}$ along the $X$-axis, $-4 \pm 7 \mu \mathrm{m}$ along the $Y$-axis, and $11 \pm$ $7 \mu \mathrm{m}$ along the $Z$-axis) using the $X Y Z$ axes indicated in Figure $1 \mathrm{C}$ ( $n=8$ cells). Thus, the average position of AP-evoking pixels predicted the position of the stimulated neuron soma with errors of no more than $12 \mu \mathrm{m}$ in each direction.

\section{Identification of dendritic spines innervated by electrically-stimulated axons}

Next, electrical stimulation of presynaptic axons was used to examine the reliability of $\mathrm{Ca}^{2+}$ imaging for the detection of $\mathrm{Ca}^{2+}$ transients in dendritic spines. Recoded layer 5 pyramidal cells were filled with $\mathrm{Ca}^{2+}$ indicator (750 $\mu \mathrm{M}$ Fluo-5F; green fluorescence, G) and fluorescent dye (45 $\mu \mathrm{M}$ Alexa Fluor 594; red fluorescence, R). An $830-\mathrm{nm}$ laser beam was used to perform $\mathrm{Ca}^{2+}$ imaging. The $\mathrm{Ca}^{2+}$ imaging regions were approximately $40 \times 10$ $\mu \mathrm{m}$ in area and included 17 to 31 dendritic spines on each layer 5 pyramidal cell. The acquisition time per imaging frame was $170-320 \mathrm{~ms}$. A stimulation pipette was inserted near the selected dendrite (eight dendritic regions in five cells). Axons adjacent to the dendrite were stimulated 10 to 20 times at $0.2-0.25 \mathrm{~Hz}$ during sequential $\mathrm{Ca}^{2+}$ imaging. The membrane potential was held at $-30 \mathrm{mV}$ to relieve the $\mathrm{Mg}^{2+}$ block of $\mathrm{N}$-methylD-aspartate receptors (NMDARs). The difference between the ratios of $G$ intensity and $R$ intensity $(G / R)$ immediately after and immediately before stimulation, $\Delta G / R_{\text {transient }}$, was divided by the mean $G / R$ before stimulation $\left(G / R_{\text {base }}\right)$ in the same spine. This ratio was defined as the amplitude of a $\mathrm{Ca}^{2+}$ transient. $\mathrm{Ca}^{2+}$ transients with amplitudes $>1$ were detected clearly in some spines immediately after a single electrical stimulation of presynaptic axons (Figure $1 \mathrm{D}-\mathrm{F}$ ). $\mathrm{Ca}^{2+}$ transients were not caused by direct electrical stimulation of the observed dendrite, since neither a large inward current with a long decay time nor a widespread rise in $\mathrm{Ca}^{2+}$ transient were observed in the dendritic shaft (Figure 1D). The success rate of $\mathrm{Ca}^{2+}$ transients (1 - failure rate of occurrence of $\mathrm{Ca}^{2+}$ transients) was $0.65 \pm 0.08$ 


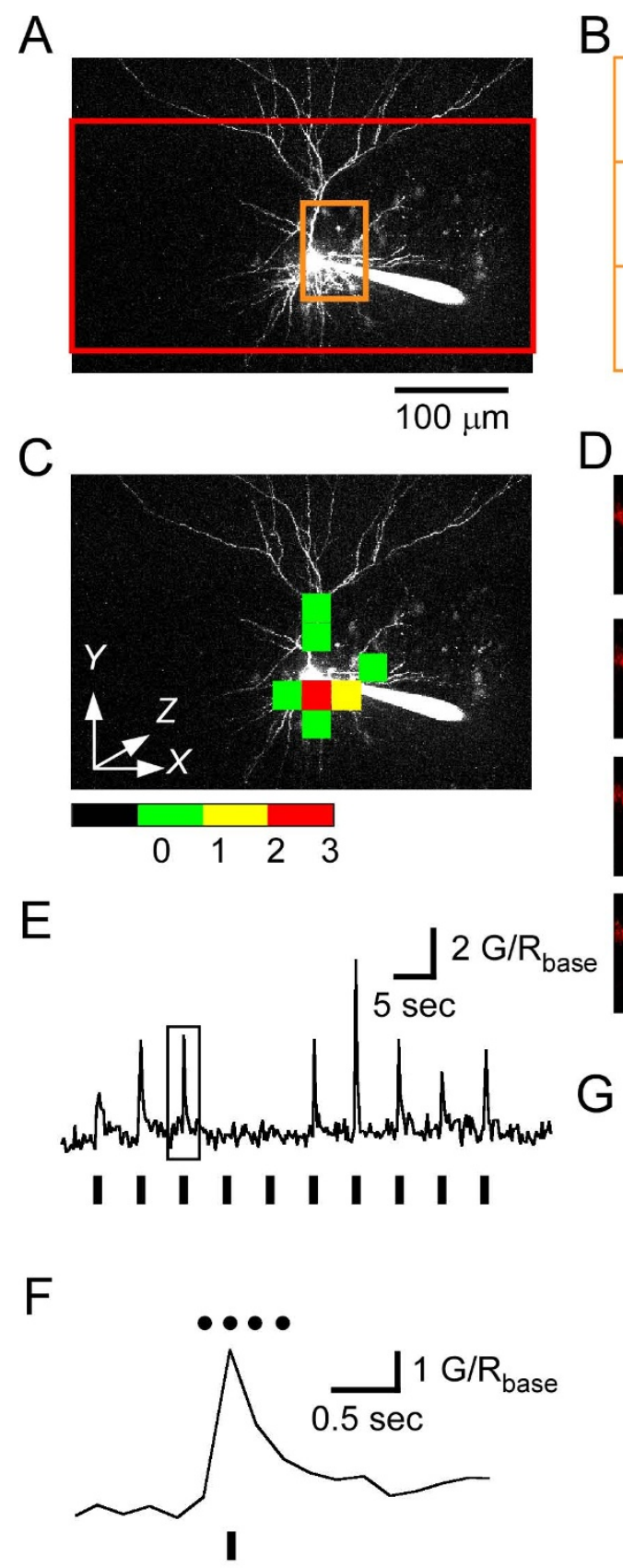

B

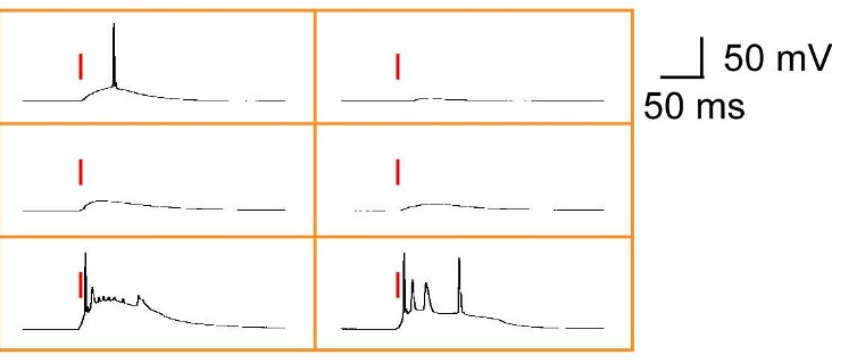

$\mathrm{D}$

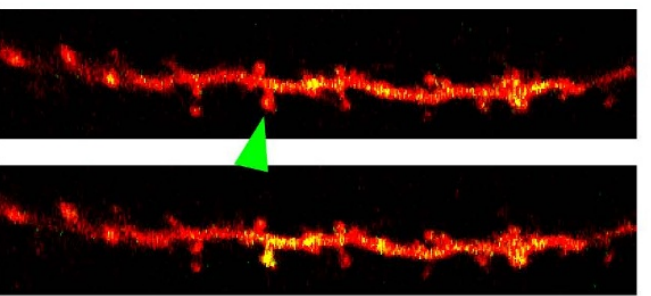

13.97

$(\mathrm{sec})$

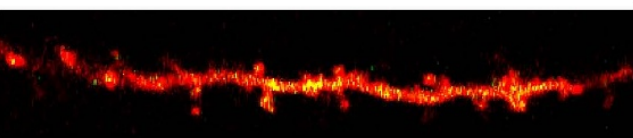

14.16

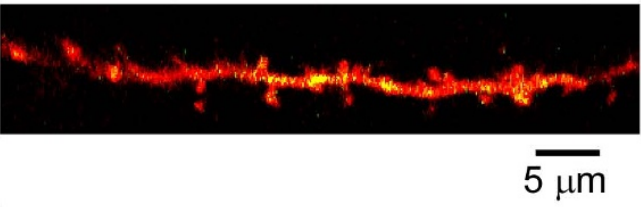

14.36

14.55

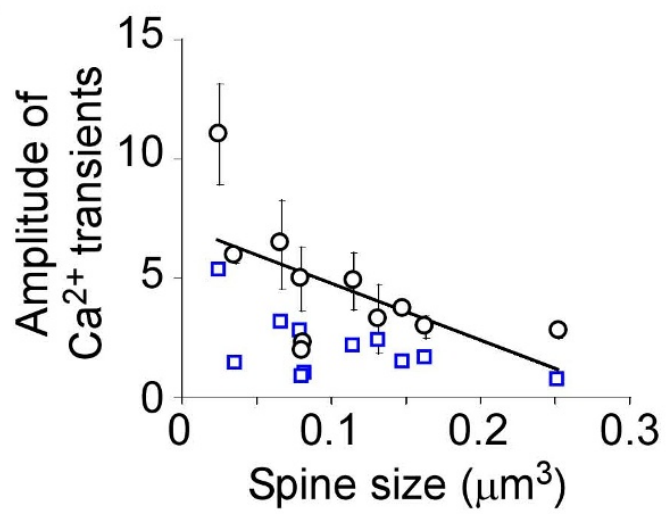

Figure 12 pMAPG induction of action potentials in a layer $2 / 3$ cell and detection of $\mathrm{Ca}^{2+}$ transients in a dendritic spine of a layer 5 cell. (A) A Z-stacked image of a representative layer 2/3 pyramidal cell filled with Alexa Fluor 594. The depth of the soma was $82 \mu \mathrm{m}$ from the slice surface. The red region was divided into $16 \times 8$ pixels in a single plane and 2 pMAPG was performed at each pixel at depths of 30,80 and $130 \mu \mathrm{m}$ from the top of the slice. (B) Each trace represents the membrane potential derived from 2pMAPG performed at each pixel in the orange-boxed region in (A) at a depth of $80 \mu \mathrm{m}$. Red bars indicate the time of 2pMAPG. (C) Green, yellow, and red pixels indicate AP-evoking pixels detected at any one of the three depths $(30,80$ or $130 \mu \mathrm{m})$, at any two of these three depths, or at all of the three depths, respectively. (D) A single electrical stimulation near the dendrite induced a $\mathrm{Ca}^{2+}$ transient in one of the dendritic spines in the imaging region (arrow). Red (Alexa Fluor 594) fluorescence and green (Fluo-5F) fluorescence are overlaid. The overlapping signals appear yellow. The time interval between images was $194 \mathrm{~ms}$. The time from the onset of sequential imaging is indicated to the right of each figure. (E) The $G$ intensity/R intensity (G/R) trace in the spine is indicated with an arrow in (D) for 10 electrical stimuli at $0.2 \mathrm{~Hz}$. (F) Expanded G/R trace is boxed in (E). Four dots indicate the acquisition times of the four imaging frames shown in (D). (G) The mean amplitudes of $\mathrm{Ca}^{2+}$ transients (black circle) and the mean 5 coefficients of variance of $\mathrm{G} / \mathrm{R}_{\text {base }}$ (blue rectangle) are plotted against spine size. The regression line for $\mathrm{Ca}^{2+}$ transients is shown. Bars, standard error of mean. 
( $n=11$ spines from five cells), which probably reflected the reliability of glutamate release. However, as this value might also reflect the failure rate for induction of the axonal AP, it is not discussed here. In successful trials, the amplitude of $\mathrm{Ca}^{2+}$ transients correlated inversely with spine size (Figure 1G; $r=-0.66, P<0.01$, Spearman's rank correlation), consistent with previous results in hippocampal cells [22]. Although $\Delta \mathrm{G} / \mathrm{R}_{\text {transient }}$ increased with decreasing spine size, the amplitude of $\mathrm{Ca}^{2+}$ transients were $>$ fivefold larger than the coefficient of variance $(\mathrm{CV})$ of $\mathrm{G} / \mathrm{R}_{\text {base }}$ in the same spine, regardless of spine size (Figure 1G; $P<0.001$, paired $t$ test). Thus, we concluded that $\mathrm{Ca}^{2+}$ transients could be reliably detected in spines of various sizes under the experimental conditions used here.

\section{Development of simultaneous 2pMAPG mapping and} $\mathrm{Ca}^{2+}$ imaging

Next, simultaneous 2pMAPG mapping and $\mathrm{Ca}^{2+}$ imaging were performed by independently scanning 720-nm and 830-nm laser beams (Figure 2). Both the mapping and imaging regions were included in the field of view under a $25 \times$ objective lens (purple box in Figure 3A). The 2 pMAPG mapping region $(500 \times 250 \mu \mathrm{m}$ in a single plane) was located in the lower region of layer $2 / 3$, while the imaging region $(\sim 50 \times 10 \mu \mathrm{m})$ included one or two dendritic branches with 10-40 spines on the recorded pyramidal cell in upper layer 5 (Figure 3A and $3 \mathrm{~B})$. In order to perform 2 pMAPG mapping at different focal planes from $\mathrm{Ca}^{2+}$ imaging, the focal plane was changed rapidly from the imaging plane to the mapping plane immediately before 2pMAPG at each point. Then, immediately after single 2pMAPG for 9 $\mathrm{ms}$, the focal plane was returned to the imaging plane. The focal plane was moved by regulating a piezo actuator attached to the objective (Figure 2 and Additional File 1: Figure S1A). However, the actuator's rapid movement caused the microscope arm supporting the objective to vibrate for more than $200 \mathrm{~ms}$ after the movement, which inhibited stable imaging of the dendritic spines at the target plane (Additional File 1: Figure S1). To absorb the vibration energy and inhibit the vibration, two rubber dampers were attached to the arm and the objective (green arrows in Additional File1:

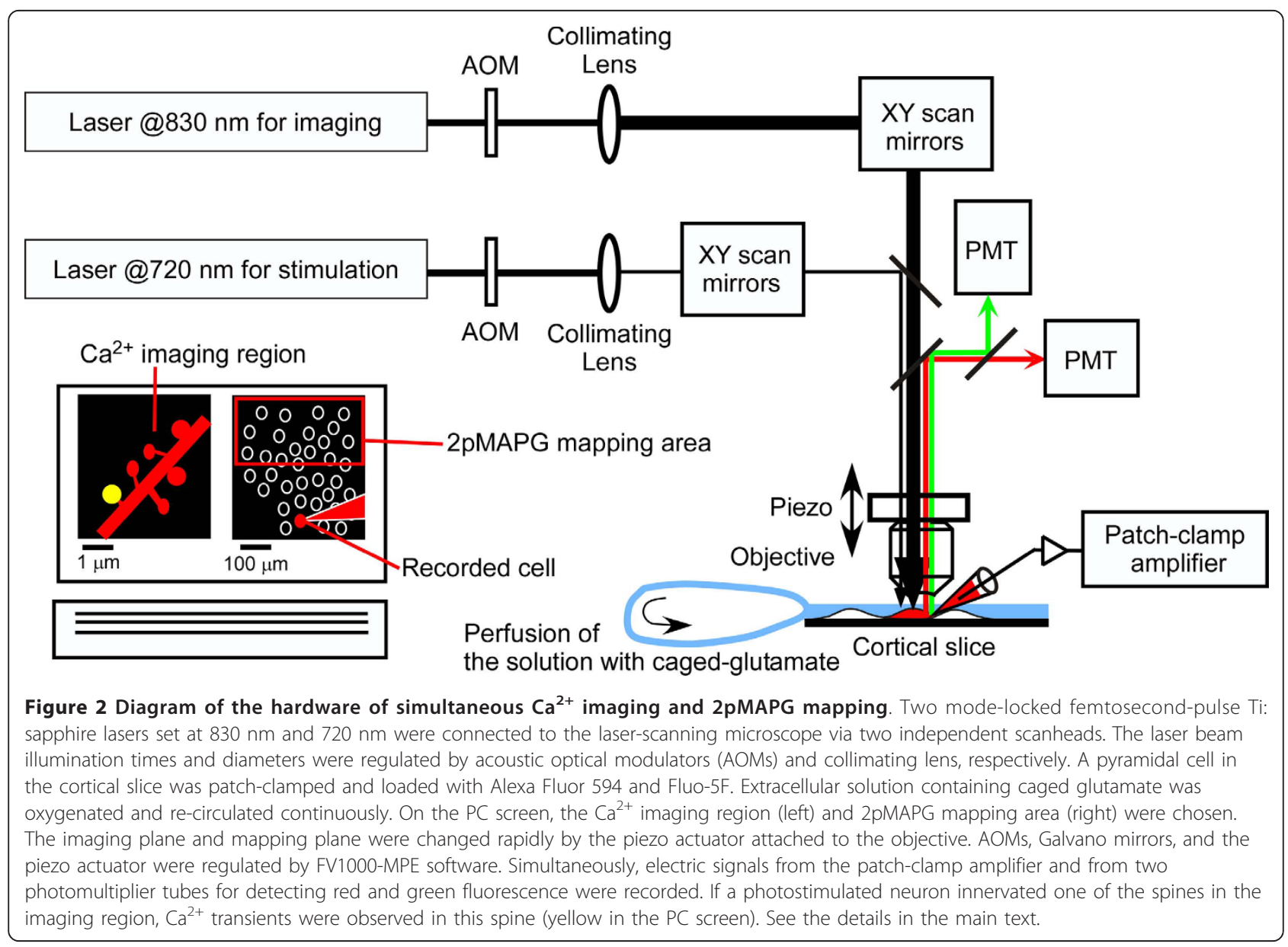




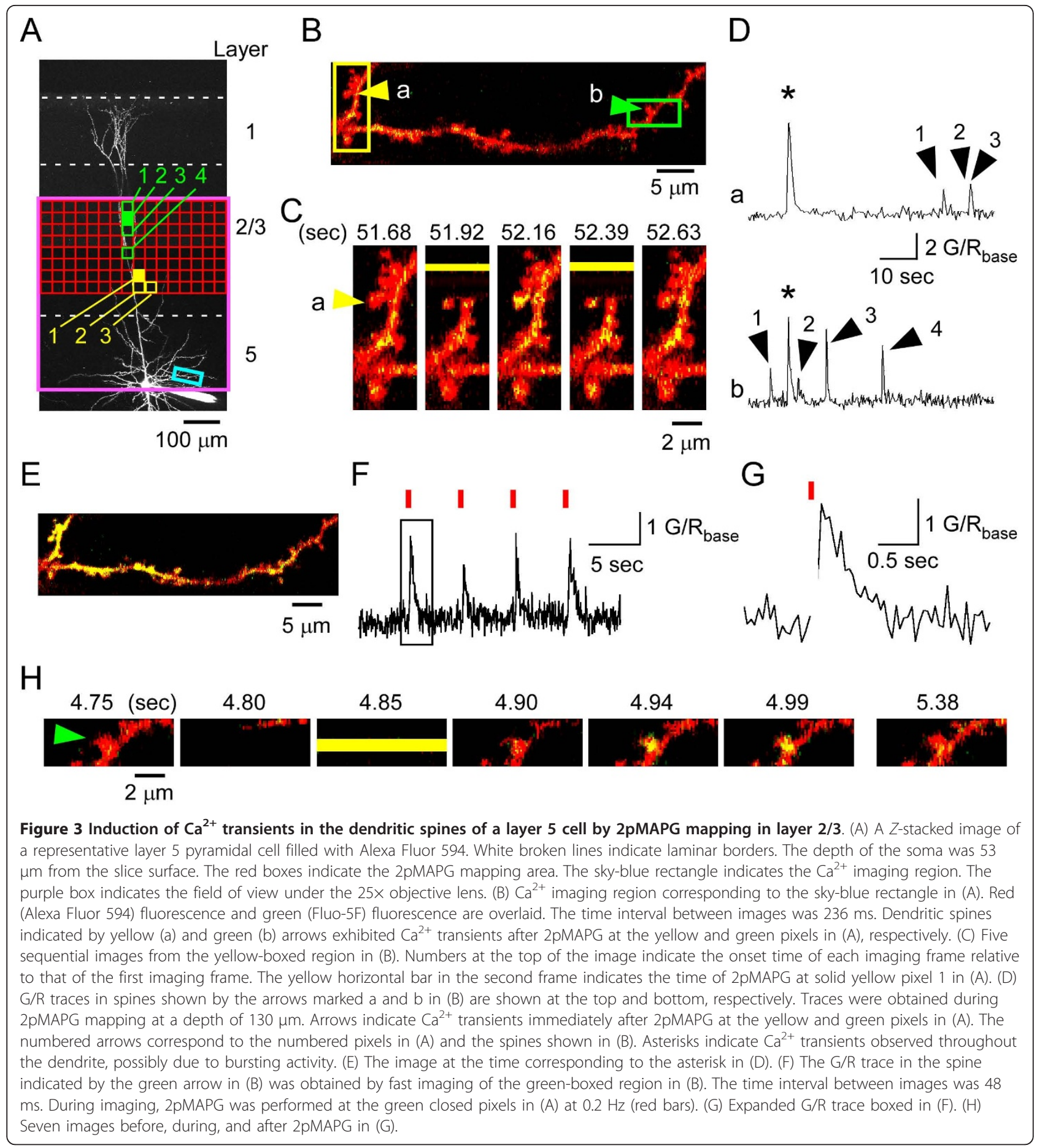

Figure S1A). Damping allowed stabilization of the focal plane at the target plane approximately $60 \mathrm{~ms}$ after the onset of axial movement (Additional File 1: Figure S1BF). The 2pMAPG interval and the frame rate of $\mathrm{Ca}^{2+}$ imaging were set at $470 \mathrm{~ms}$ and $150-340 \mathrm{~ms}$, respectively. In this condition, dendritic spines in the imaging plane could be imaged at least once for $\sim 60-400 \mathrm{~ms}$ following completion of one 2pMAPG and prior to the start of the next axial movement (Figure $3 \mathrm{C}$ and $3 \mathrm{H}$ ). The mean time from the onset of photostimulation to the peak of the $\mathrm{Ca}^{2+}$ transient was $173 \pm 16 \mathrm{~ms}(n=4$ spines). Thus, the $\mathrm{Ca}^{2+}$ transient in a spine was thought to be detected in the first or second imaging frame immediately after 2pMAPG, if the spine was innervated 
by one of the photostimulated cells. For each mapping plane, complete 2pMAPG at 128 points required $\sim 60 \mathrm{~s}$ $(128 \times 470 \mathrm{~ms})$. Following completion of mapping in one plane, the mapping plane was changed to the next depth, and then 2pMAPG mapping and $\mathrm{Ca}^{2+}$ imaging were again performed simultaneously. Mapping was carried out at 3 depths at intervals of $50 \mu \mathrm{m}$.

Reliable measurement of the amplitude or number of excitatory postsynaptic currents (EPSCs) induced by 2pMAPG could not be achieved due to the following experimental side-effects. First, axial movement of the objective caused electric artifacts that continued for $>50$ $\mathrm{ms}$ after the end of 2pMAPG in the whole-cell current measurement (Additional File 1: Figure S1G). Second, since the holding potential was maintained at $-30 \mathrm{mV}$, the driving force of the cation influx was weaker than at $-70 \mathrm{mV}$ and the amplitudes of unitary EPSCs were relatively small $(<10 \mathrm{pA})$. Thus, only $\mathrm{Ca}^{2+}$ transients could be considered as synaptic inputs unless otherwise noted.

\section{Identification of dendritic spines on a layer 5 pyramidal cell innervated by layer $2 / 3$ pyramidal cells}

During 2pMAPG mapping, $\mathrm{Ca}^{2+}$ transients were detected in one to three dendritic spines in the first or second imaging frame after 2pMAPG (Figure 3B to 3D). These $\mathrm{Ca}^{2+}$ transients were specific to individual spines and could be distinguished from global $\mathrm{Ca}^{2+}$ increases arising from dendritic spikes possibly triggered by bursting activity (Figure 3E). Following reconstruction of the pixels for 2pMPAG, which were assumed to induce $\mathrm{Ca}^{2+}$ transients, it became apparent that these pixels were frequently attached to each other laterally or axially within the 3D mapping region (yellow pixels in Figure 3A). This finding strongly suggests that one of the neurons associated with these pixels innervated the dendritic spine exhibiting $\mathrm{Ca}^{2}$ ${ }^{+}$transients, since most AP-evoking pixels (59/63 pixels in eight cells) possessed neighbouring AP-evoking pixels when layer $2 / 3$ pyramidal cells were stimulated by 2pMAPG mapping. However, $\mathrm{Ca}^{2+}$ transients were also detected occasionally in a dendritic spine immediately after 2PMAPG at a given pixel, even though neighboring pixels showed no $\mathrm{Ca}^{2+}$ transient associated with 2pMAPG. These $\mathrm{Ca}^{2+}$ transients might occur spontaneously in a dendritic spine. In order to avoid such contamination, $\mathrm{Ca}^{2+}$ transients were considered to be induced by 2pMAPG when they occurred immediately after 2pMAPGs in at least two neighbouring pixels within a distance of less than $65 \mu \mathrm{m}$ (approximately the length of two pixels; Additional File 2: Figure S2). These pixels are referred to as grouped $\mathrm{Ca}^{2+}$ transient-evoking pixels (Additional File 2: Figure S2).

For further determination of the reliability of 2pMAPG-induced $\mathrm{Ca}^{2+}$ transients, 2pMAPG was performed repeatedly at one of the grouped $\mathrm{Ca}^{2+}$ transient- evoking pixels with fast $\mathrm{Ca}^{2+}$ imaging $(n=4$ spines in three cells). Figure $3 \mathrm{~F}-\mathrm{H}$ shows representative $\mathrm{Ca}^{2+}$ transients from one of these spines. The mean success rate in 10 trials was $0.95 \pm 0.03$ ( $n=4$ spines). If the laser intensity for 2pMAPG was reduced, neither $\mathrm{Ca}^{2+}$ transients nor putative postsynaptic currents were evoked (Additional File 3: Figure S3). These findings indicate that 2pMAPG reliably triggered $\mathrm{Ca}^{2+}$ transients in the spines, and they were not evoked by unrelated, spontaneous glutamate release from presynaptic boutons.

Altogether, $\mathrm{Ca}^{2+}$ transients induced by 2 pMAPG at grouped $\mathrm{Ca}^{2+}$ transient-evoking pixels were detected in 34 spines in $25 \mathrm{Ca}^{2+}$ imaging regions of 18 layer 5 pyramidal neurons. Various sizes of spines exhibited $\mathrm{Ca}^{2+}$ transients (Figure 4A to $4 \mathrm{C}$ ), and their distribution was similar to that of all the imaged spines (Figure 4D and $4 \mathrm{E})$. The mean and median sizes of all the imaged spines were $0.13 \mu \mathrm{m}^{3}$ and $0.10 \mu \mathrm{m}^{3}$, respectively. The size distribution appeared lognormal, skewing toward large spines, as previously reported in hippocampal pyramidal cells $[8,23]$. In contrast to the single electrical stimulation (Figure 1G), no inverse relationship between spine size and the amplitude of the $\mathrm{Ca}^{2+}$ transient was detected (Figure 4F; $r=-0.22, P=0.75$, Spearman's rank correlation), possibly because the amplitudes of the $\mathrm{Ca}^{2+}$ transients in four of six large spines $\left(>0.3 \mu \mathrm{m}^{3}\right)$ were $>5$. If the reliability of glutamate release tended to be higher with the increase in spine size, as reported in hippocampal synapses, $[24,25]$ each of the multiple APs induced by a single 2pMAPG might consistently release glutamate in the four large spines, resulting in large $\mathrm{Ca}^{2}$ ${ }^{+}$transients.

\section{Convergence of synaptic inputs on the same dendritic branch}

$\mathrm{Ca}^{2+}$ transients were detected in 1,2 and 3 dendritic spines from 7, 6 and 5 recorded cells, respectively. The positional relationships of $21(6 \times 1+5 \times 3)$ pairs of responding spines were analyzed along with the frequency with which the same presynaptic cell innervated spines on the same dendritic branch. In two instances, 2pMAPG at one group of pixels simultaneously induced $\mathrm{Ca}^{2+}$ transients in a pair of spines in the same imaging region (Figure 5A and 5B). One pair of spines consistently demonstrated $\mathrm{Ca}^{2+}$ transients after stimulation of the same seven pixels in the corresponding mapping region (Figure 5A); in the other pair, $\mathrm{Ca}^{2+}$ transients were induced by 2 pMAPG at the same 12 pixels in the corresponding mapping region (Figure $5 \mathrm{~B}$ ). These results indicate that each pair of spines was innervated by the same presynaptic neuron.

In the remaining 19 pairs of dendritic spines, $\mathrm{Ca}^{2+}$ transients were induced by 2 pMAPG at different grouped $\mathrm{Ca}^{2+}$ transient-evoking pixels, which suggests 


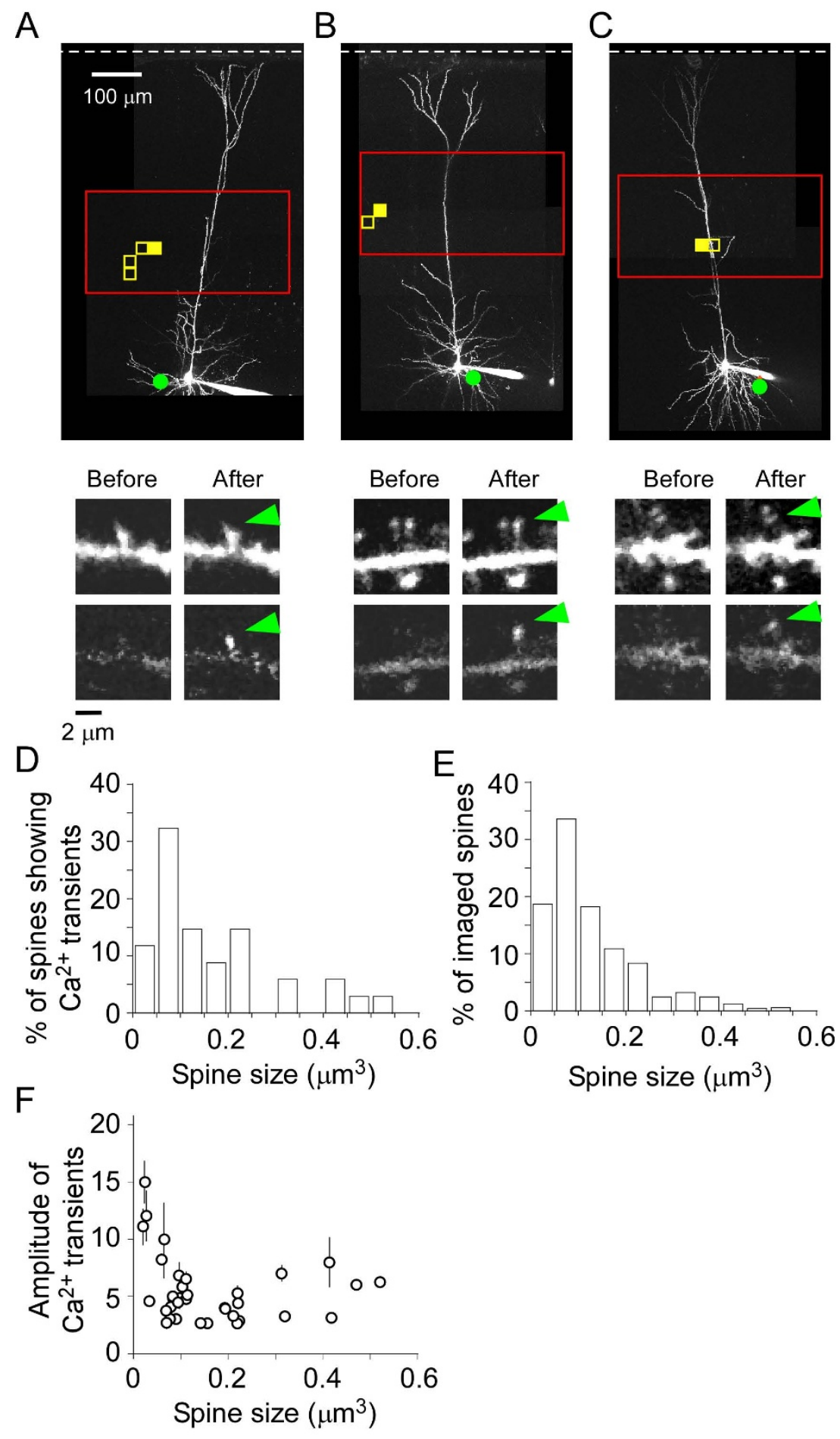

Figure 4 Spines of various sizes show $\mathrm{Ca}^{2+}$ transients in response to 2 pMAPG. (A-C) Three examples of 2 pMAPG mapping and $\mathrm{Ca}^{2+}$ imaging. The top panels show grouped $\mathrm{Ca}^{2+}$ transient-evoking pixels (yellow pixels) and dendritic spines that exhibited $\mathrm{Ca}^{2+}$ transients induced by 2pMAPG (green dots indicate the position of these spines). Red boxes show 2pMAPG mapping areas. White broken lines indicate the pial surface. In the middle and bottom images, green arrows indicate the spines with $\mathrm{Ca}^{2+}$ transients. These images were taken from larger $\mathrm{Ca}^{2+}$ imaging regions. The middle and lower panels show Alexa Fluor 594 and Fluo-5F fluorescence, respectively. The images were taken immediately before and after 2pMAPG at the solid yellow pixels shown in the top panels. (D) The size distribution of spines showing $\mathrm{Ca}^{2+}$ transients in the first or second imaging frame after 2pMAPG ( $n=34$ in 18 cells). (E) The size distribution of all spines included in the imaging regions ( $n=494$ in 18 cells). (F) The mean amplitudes of $\mathrm{Ca}^{2+}$ transients are plotted against spine size. Bars, standard error of mean. 


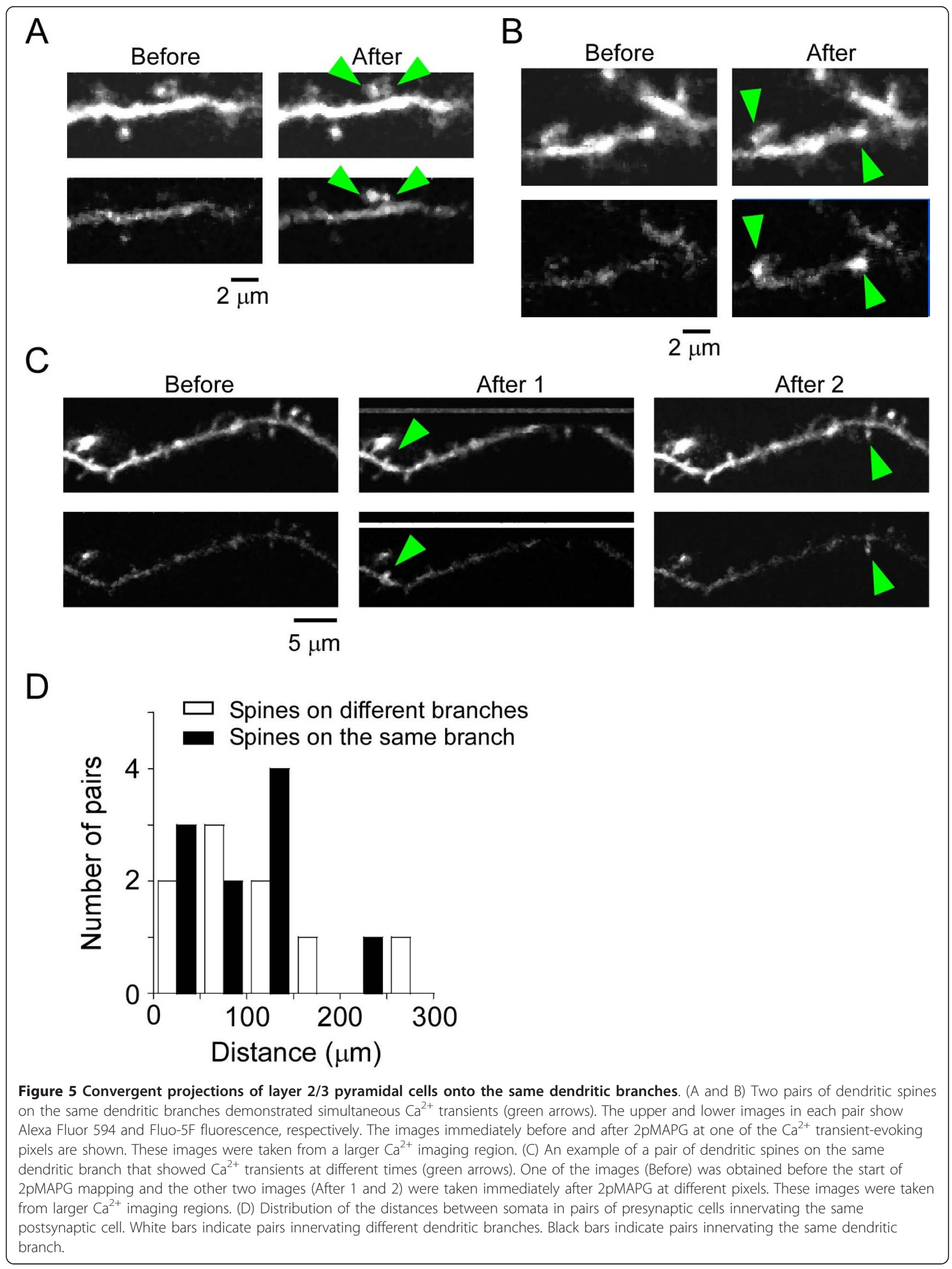


that these spines were innervated by different presynaptic neurons. Ten pairs of spines were located on the same dendritic branches, at mean distances of $18 \pm 4$ $\mu \mathrm{m}(2-37 \mu \mathrm{m})$. An example is shown in Figure $5 \mathrm{C}$. Nine pairs were located on different dendritic branches of the same postsynaptic cells.

The average position of the grouped $\mathrm{Ca}^{2+}$ transientevoking pixels was used to predict the position of the presynaptic cells. In order to ascertain whether or not this determination was valid, we reexamined the data for AP induction of layer $2 / 3$ pyramidal cells described in the first part of the Results. Using the same criteria as for the grouped $\mathrm{Ca}^{2+}$ transient-evoking pixels, APevoking pixels with neighbouring AP-evoking pixels are referred to as grouped AP-evoking pixels. The differences between the average position of the grouped APevoking pixels and the centre of the soma were $-14 \pm 16$ $\mu \mathrm{m}$ along the $X$-axis, $5 \pm 8 \mu \mathrm{m}$ along the $Y$-axis, and 14 $\pm 7 \mu \mathrm{m}$ along the $Z$-axis $(n=8$ cells). Thus, the average position of grouped AP-evoking pixels represented the approximate position of the stimulated neuron soma. The number of grouped AP-evoking pixels per layer 2/3 cell was $7.4 \pm 0.5(n=8$ cells $)$, which was more than the number of grouped $\mathrm{Ca}^{2+}$ transient-evoking pixels per spine $(5.2 \pm 0.5, n=34$ spines; $P<0.05$, MannWhitney $U$ test). This difference may be due to some AP-evoking pixels with a single AP failing to induce $\mathrm{Ca}^{2+}$ transients in the spine. Assuming that the distribution of grouped $\mathrm{Ca}^{2+}$ transient-evoking pixels was similar to that of grouped AP-evoking pixels, the average position of grouped $\mathrm{Ca}^{2+}$ transient-evoking pixels can be defined as the position of a presynaptic neuron innervating a dendritic spine showing $\mathrm{Ca}^{2+}$ transients.

The distances between the average positions of grouped $\mathrm{Ca}^{2+}$ transient-evoking pixels were calculated. No significant difference in distance from the somata was detected between spine pairs on the same dendritic branch and those on different dendritic branches (Figure 5D; $97 \pm$ $18 \mu \mathrm{m}, n=10$ pairs versus $104 \pm 27 \mu \mathrm{m}, n=9$ pairs, respectively; $P=0.87$, Mann-Whitney $U$ test). In addition, no more than two presynaptic neurons innervating the same dendritic branch within an imaging region could be detected in any 100- $\mu \mathrm{m}$ spherical area. Thus, despite the very small number of dendritic spines showing $\mathrm{Ca}^{2+}$ transients on the same dendritic branch, layer $2 / 3$ presynaptic neurons innervating the same dendritic branch did not appear to be clustered more clearly or frequently than those innervating scattered spines.

\section{Relationship between the structure and function of dendritic spines on layer $\mathbf{5}$ pyramidal cells}

New 3D coordinates were defined to clarify the relationships between the size and location of innervated dendritic spines and the locations of pre- and postsynaptic neuronal somata (Figure 6A). (1) The postsynaptic neuronal soma is set at the centre of the coordinates $(0,0,0)$. (2) The main apical dendrite of the postsynaptic neuron is assumed to be in a line that follows the positive $Y$ axis. (3) The location of each identified spine is aligned at $\left(x_{\mathrm{sp}}, y_{\mathrm{sp}}, 0\right)$ in the $X Y$ plane with $x_{\mathrm{sp}}>0$. Thus, $x_{\mathrm{sp}}$ indicates the lateral distance between the dendritic spine and the soma. (4) In this 3D coordinate system, $\left(x_{\text {pre }}, y_{\text {pre }}, z_{\text {pre }}\right)$ is defined as the position of the presynaptic neuron innervating the dendritic spine showing $\mathrm{Ca}^{2+}$ transients, as described above.

First, we examined the relationships between spine size and each of the positional parameters. Spine size did not correlate with $x_{\mathrm{sp}}$, which varied from 20 to 140 $\mu \mathrm{m}(r=0.05, n=34, P=0.77$; Spearman's rank coefficient). Spines were classified into four groups according to size (Figure 6B; spines of $0-0.1 \mu \mathrm{m}^{3}, n=15 ; 0.1-0.2$ $\mu \mathrm{m}^{3}, n=8 ; 0.2-0.3 \mu \mathrm{m}^{3}, n=5$ and $\left.>0.3 \mu \mathrm{m}^{3}, n=6\right)$. The lateral distance between the postsynaptic and presynaptic somata $\sqrt{x_{\text {pre }}{ }^{2}+z_{\text {pre }}{ }^{2}}$, and the lateral distance between the dendritic spine and the presynaptic soma $\sqrt{\left(x_{\text {pre }}-x_{s p}\right)^{2}+z_{\text {pre }}{ }^{2}}$, were not significantly different across the four groups (Figure $6 \mathrm{C} ; P=0.68$ and 0.39 , respectively, one-way ANOVA). The straight-line distance of the dendritic spine from the presynaptic soma $\sqrt{\left(x_{p r e}-x_{s p}\right)^{2}+\left(y_{p r e}-y_{s p}\right)^{2}+z_{p r e}^{2}}$, was significantly longer in spines of 0-0.1 $\mu^{3}$ than in those of 0.1-0.2 $\mu \mathrm{m}^{3}$ (Figure 6C; $P<0.05$, one-way ANOVA followed by Tukey's test). Presynaptic cells innervating spines of $>0.2 \mu \mathrm{m}^{3}$ were preferentially distributed in the field ipsilateral to the spine (nine of 11 cells; orange and red closed circles in Figure 6B). In fact, the $x_{\text {pre }}$ of spines $>0.2 \mu \mathrm{m}^{3}$ was significantly greater than that of spines $<0.2 \mu \mathrm{m}^{3}$ (Figure 6D; $83 \pm 20 \mu \mathrm{m}$ versus $3 \pm 25 \mu \mathrm{m}$, respectively; $P<0.05$, Mann-Whitney $U$ test). However, no significant differences in $x_{\text {pre }}$ were detected between the four size groups (Figure $6 \mathrm{D} ; P=0.11$, one-way ANOVA).

We next examined the relationships between spine location $\left(x_{\mathrm{sp}}\right)$ and each of the other positional parameters. Spines were classified into four groups according to $x_{\mathrm{sp}}$ (Figure 7A; spines with an $x_{\mathrm{sp}}$ of $0-40 \mu \mathrm{m}$, $n=6$; 40-80 $\mu \mathrm{m}, n=14 ; 80-120 \mu \mathrm{m}, n=11$; and $>120$ $\mu \mathrm{m}, n=3)$. No significant difference in the lateral distance of the postsynaptic soma from the presynaptic soma, the lateral distance of the dendritic spine from the presynaptic soma, or the straight-line distance of the dendritic spine from the presynaptic soma was detected across groups (Figure 7B; $P=0.81,0.32$ and 


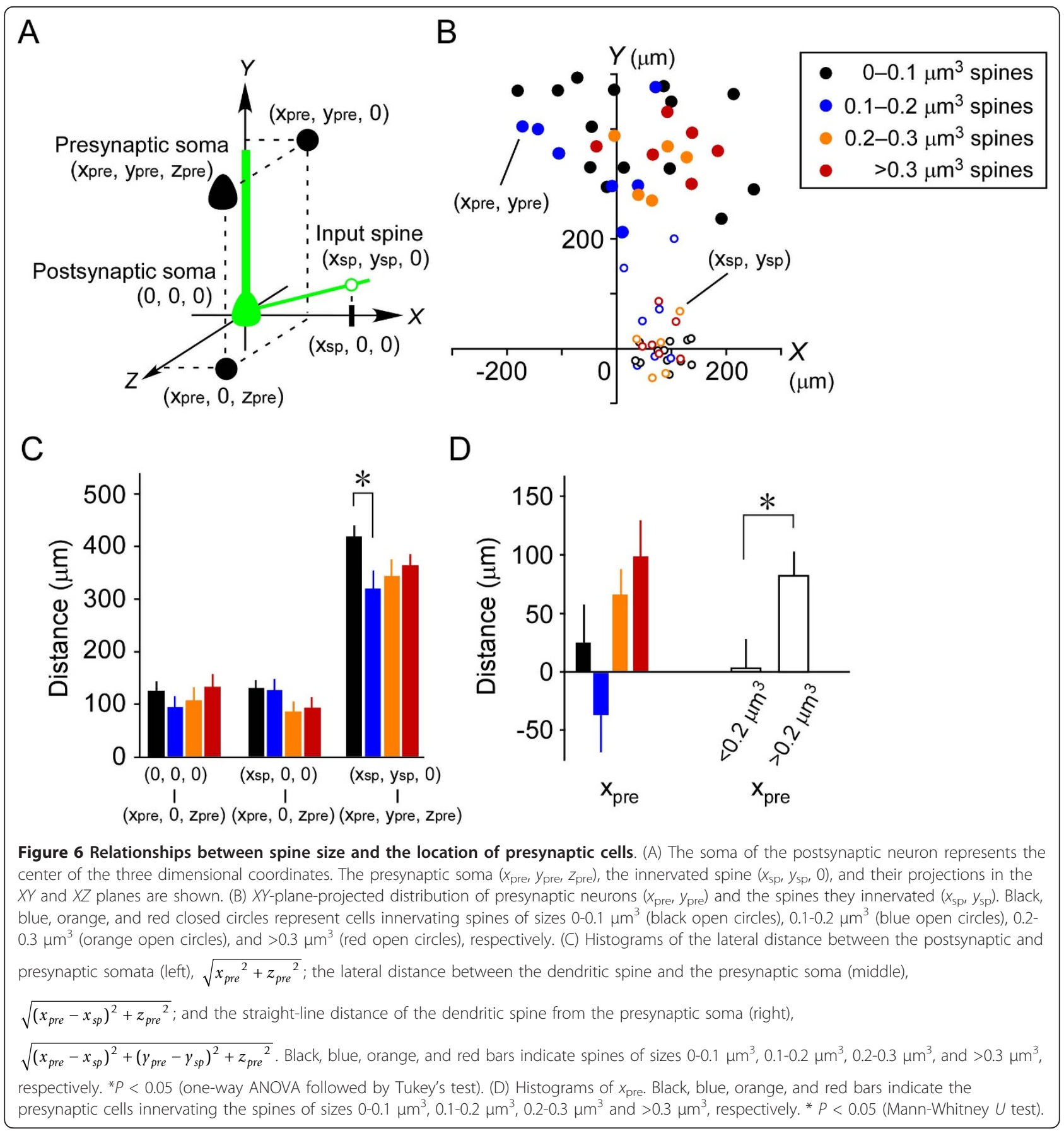

0.51 , respectively, one-way ANOVA). However, $x_{\text {pre }}$ in the $0-40-\mu \mathrm{m}$ group was significantly different from the other groups (Figure $7 C ; P<0.05$, one-way ANOVA followed by Tukey's test). This difference was supported by the fact that $x_{\text {pre }}$ correlated with $x_{\mathrm{sp}}(r=$ $0.46, P<0.01$, Spearman's rank coefficient). It is unlikely that this difference was due to the cutting of axon fibers during the slice preparation, since $y_{\text {pre }}$ did not correlate with $y_{\mathrm{sp}}(r=0.25, P=0.15$, Spearman's rank coefficient). These results suggest that more laterally located dendritic spines received synaptic inputs from laterally located cells in the field ipsilateral to the spine, independent of the lateral distance between the presynaptic soma and the dendritic spine. 


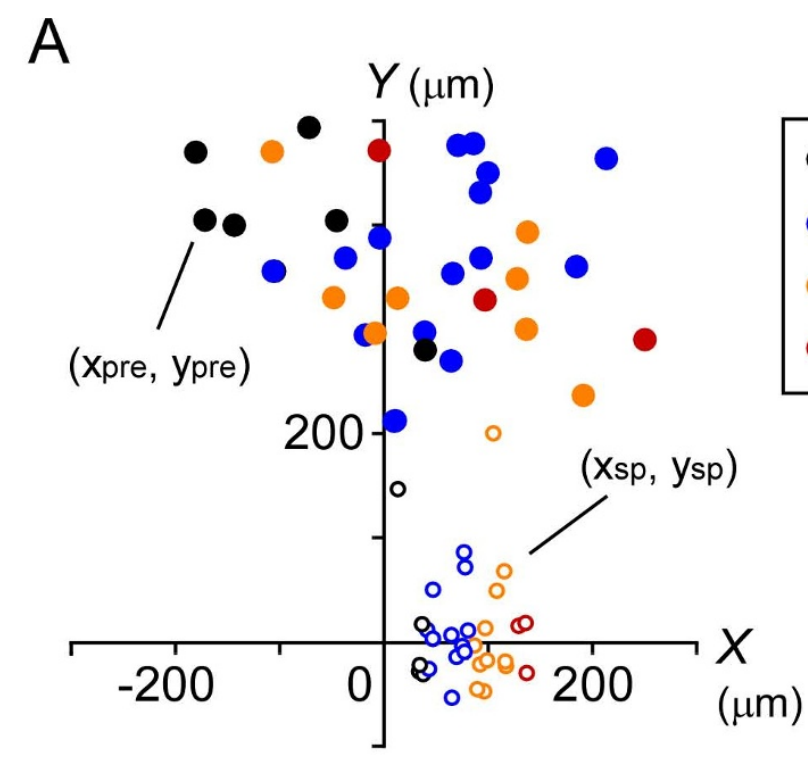

B

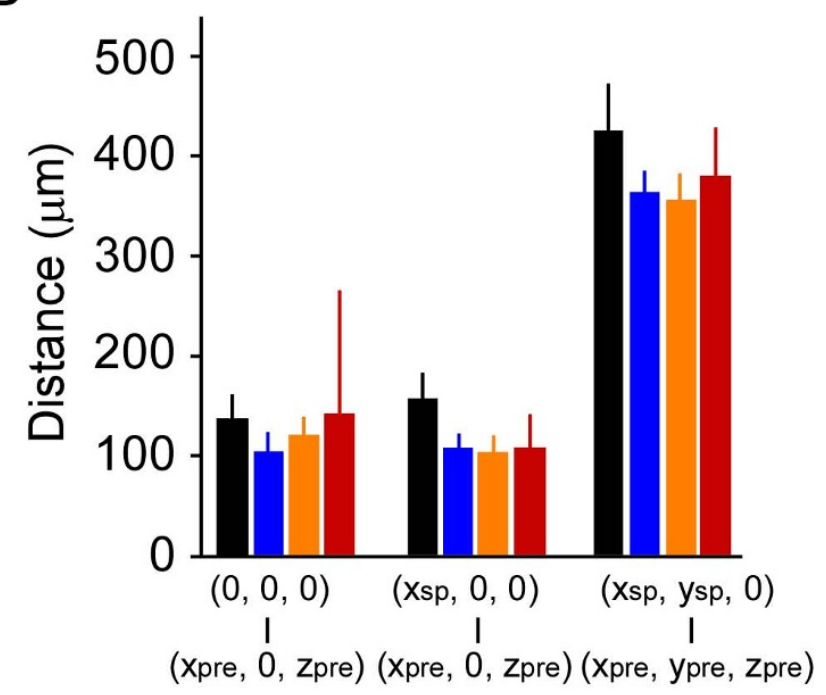

C

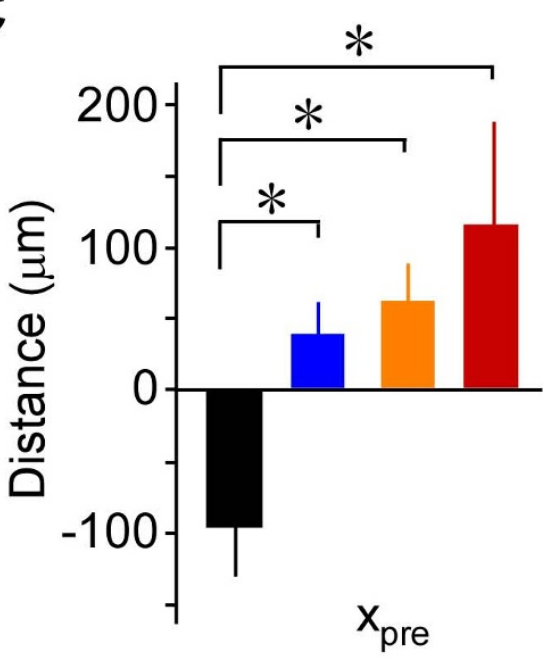

Figure 7 Relationships between spine location and the location of the presynaptic cells. (A) XY-plane-projected distribution of presynaptic neurons $\left(x_{\text {pree }}, y_{\text {pre }}\right)$ and the spines they innervated $\left(x_{\text {sp }}, y_{\text {sp }}\right)$. Black, blue, orange and red closed circles represent the cells innervating spines with an $x_{\text {sp }}$ of 0-40 $\mu \mathrm{m}$ (black open circles), 40-80 $\mu \mathrm{m}$ (blue open circles), 80-120 $\mu \mathrm{m}$ (orange open circles), and >120 $\mu \mathrm{m}$ (red open circles),

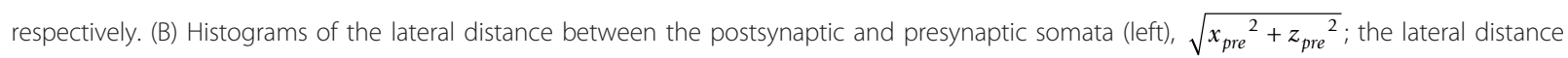
between the dendritic spine and the presynaptic soma (middle), $\sqrt{\left(x_{p r e}-x_{s p}\right)^{2}+z_{p r e}^{2}}$; and the straight-line distance of the dendritic spine from the presynaptic soma (right), $\sqrt{\left(x_{\text {pre }}-x_{s p}\right)^{2}+\left(y_{\text {pre }}-y_{s p}\right)^{2}+z_{\text {pre }}{ }^{2}}$. Black, blue, orange and red bars indicate spines with an $\mathrm{x}_{\mathrm{sp}}$ of 0-40 $\mu \mathrm{m}, 40-80$ $\mu \mathrm{m}, 80-120 \mu \mathrm{m}$, and 120-160 $\mu \mathrm{m}$, respectively. (C) Histograms of $x_{\text {pre. }}$ Black, blue orange and red bars indicate the presynaptic cells innervating the spines with an $x_{\mathrm{sp}}$ of 0-40 $\mu \mathrm{m}, 40-80 \mu \mathrm{m}, 80-120 \mu \mathrm{m}$ and 120-160 $\mu \mathrm{m}$, respectively. ${ }^{*} P<0.05$ (one-way ANOVA followed by Tukey's test). 


\section{Discussion}

This study developed a novel method for simultaneously performing $\mathrm{Ca}^{2+}$ imaging in a narrow region that includes a segment of a dendrite, and 2pMAPG across a broad area that includes many pyramidal cells. The methodological focus was the simultaneous use of two two-photon lasers that over- and under-filled the back aperture of the objective for $\mathrm{Ca}^{2+}$ imaging of dendritic spines and photostimulation of neurons, respectively. It was important to inhibit vibration of the objective, which accompanied the rapid axial movement between the imaging plane and the photostimulation plane. This inhibition was achieved by attaching dampers to the objective. This novel method allowed identification of spines innervated by some of the systematically stimulated neurons over a relatively broad 3D area.

In contrast to a paired recording where the presynaptic cell is identified precisely, this method required prediction of the location of the presynaptic cell from the grouped $\mathrm{Ca}^{2+}$ transient-evoking pixels. The $\mathrm{Ca}^{2+}$ transient might be generated by a directly photostimulated presynaptic cell or by a presynaptic cell synaptically activated by multiple photostimulated neurons. To clarify this issue, we estimated the number of AP-evoking cells per 2pMAPG $\left(\mathrm{N}_{\mathrm{APcell}}\right)$. According to our previous report, [7] $\mathrm{N}_{\text {APcell }}$ is estimated as $\mathrm{N}_{\text {APpixel }} \times \mathrm{V}_{\text {pixel }} \times \rho_{\text {cell }}$, where $\mathrm{N}_{\text {APpixel }}$ is the number of AP-evoking pixels per cell during 2pMAPG mapping, $V_{\text {pixel }}$ is the volume of a single pixel for 2pMAPG, and $\rho_{\text {cell }}$ is the density of excitatory pyramidal neurons. Assuming that $\mathrm{N}_{\mathrm{APpixel}}, \mathrm{V}_{\text {pixel }}$, and $\rho_{\text {cell }}$ in layer $2 / 3$ were $7.9,31 \times 31 \times 50 \mu \mathrm{m}$, and $6.8 \times$ $10^{-5} \mu^{-3}$ [7], respectively, the $\mathrm{N}_{\mathrm{APcell}}$ in layer $2 / 3$ was 26 .

According to Holmgren et al., [26] the connection probability between nearby (distance of $<25 \mu \mathrm{m}$ ) layer $2 / 3$ pyramidal neurons is 0.18 , and the average amplitude of excitatory post-synaptic potentials (EPSPs) between connected pairs of neurons is $0.65 \mathrm{mV}$. Thus, if the APs induced in 26 nearby cells simultaneously depolarize a postsynaptic cell, its depolarization is estimated at $26 \times 0.18 \times 0.65=3 \mathrm{mV}$. Even if each of the stimulated cells generated three APs simultaneously, the total synaptic depolarization will be $9 \mathrm{mV}$, which is not large enough to generate an AP in the postsynaptic cell. In fact, at any 2pMAPG pixel that was not associated with the soma or proximal dendrites of the recorded cell, no AP was induced in a recorded layer $2 / 3$ cell during 2pMAPG mapping. However, if 2pMAPG directly depolarized a cell near the stimulated pixel and its depolarization did not reach the threshold for generation of an AP, synaptic inputs from its nearby photostimulated cells might assist the cell to generate an AP. If so, such pixels should have been involved in grouped AP-evoking pixels during the mapping of AP induction, which were used for the prediction of neuronal position. Thus, the approximate position of the presynaptic cell could be determined from the positions of the grouped $\mathrm{Ca}^{2+}$-evoking pixels, although the exact cell cannot be identified.

We found that the distribution of innervating neurons in the local neocortical circuits appears to depend upon the lateral distance of the dendrite from the soma. This finding does not contradict the results of anatomical studies in which overlapping axonal and dendritic arbors were reconstructed $[16,17,27-30]$. Axons and dendrites tend to extend isotropically from the soma, and the density of their arbors decreases laterally over a few hundred microns. Thus, if presynaptic neurons are located on one side of the postsynaptic cell, the presynaptic axons would overlap with dendrites on the same side of the postsynaptic cell more frequently than those on the other side. We also found that large spines $\left(>0.2 \mu \mathrm{m}^{3}\right)$ tended to be innervated by cells on the ipsilateral side, while small spines $\left(<0.2 \mu \mathrm{m}^{3}\right)$ tended to be innervated by cells on both sides. These findings suggest that each dendritic branch may have a different receptive field in which the innervating neurons are located, and that this receptive field may be mediated primarily by large spines. However, it should be noted that synapses with a very low release probability or very low expression of NMDAR may be underestimated under the conditions used in this study.

It can be assumed theoretically that a functionallyassociated group might innervate a specific dendritic branch of the postsynaptic cell to generate a nonlinear summation of synaptic inputs in the local dendrite [31-33]. In some invertebrates and vertebrates, distinct sensory inputs induce $\mathrm{Ca}^{2+}$ signals in specific dendrites in the visual and auditory systems [13,34]. In the mammalian neocortex, functionally-associated cells are assumed to connect with each other with a higher probability, forming microcircuits [35-37]. However, these cells are not necessarily neighbours and, in this study, no clear clustering of presynaptic cells innervating the same dendritic branch was observed. Candidates for functionally connected and associated groups include subsets of neurons derived from the same stem cell [38] and subsets of the neurons innervating the same brain area $[19,39]$. These subsets of neurons can be visualized specifically, and 2pMAPG can be used to stimulate visually-identified neurons at the level of a single cell [6]. Thus, the detection method described here will allow clarification of whether or not such groups of neurons innervate the same dendritic branch, what part of dendrites they innervate, and what size of spines they innervate.

Two limitations to the present method need to be overcome in the future. First, the present rate of $\mathrm{Ca}^{2+}$ imaging is not fast enough to observe more than $\sim 100$ 
spines at once. In this study, the maximum number of spines that could be imaged simultaneously was 40 , which represents only a few percent of the total number of spines on a single pyramidal cell. In order to observe more than a hundred scattered dendritic spines, 3D arbitrary movement of the scanning points will be useful [40]. Second, this study was performed using slice preparations and, inevitably, axon fibres crossing the cutting plane were severed. The depth of the mapping area was also limited by slice thickness. Thus, it was difficult to clarify the distribution of all the presynaptic neurons innervating all the spines in the imaging region. Ideally, the mapping and imaging should be performed in vivo. In vivo $\mathrm{Ca}^{2+}$ imaging of dendritic spines has been reported, whereas in vivo two-photon uncaging of glutamate has not. However, 2pMAPG will be more applicable to in vivo studies than ultraviolet photostimulation, since the infrared (720-nm) light required for 2pMAPG can penetrate deeper into brain tissue than ultraviolet light with one-photon excitation. It has been reported recently that a newly-developed caged glutamate, $\mathrm{RuBi}$ glutamate, can be activated by two-photon excitation at the longer wavelength of $800 \mathrm{~nm}$ [41]. Alternatively, two-photon stimulation of Channelrhodopsin-2 (ChR2), a light-gated cation channel, might be more applicable to in vivo stimulation, since ChR2 excitation does not require the perfusion of any exogenous agent within the brain. In addition, the longer wavelength used for ChR2 excitation $(920 \mathrm{~nm})$ will stimulate a deeper cortical area than can be achieved with either CDNI- or RuBi-glutamate. As a large excitation volume is essential for twophoton excitation of ChR2 (MM unpublished data) [42], two-photon macro stimulation will be effective. Development of novel caged compounds and ChR2 variants will improve the performance of two-photon stimulation of neurons in vivo. In the future, specific clusters or specific distributions of presynaptic cells that could not be detected in this study may be revealed by combining photostimulation and fast $\mathrm{Ca}^{2+}$ imaging of more than 100 spines in vivo.

\section{Conclusions}

This study developed a novel method for simultaneously performing $\mathrm{Ca}^{2+}$ imaging in a narrow region that includes a segment of a dendrite and 2pMAPG across a broad area that includes many pyramidal cells. This technique allowed identification of various sizes of innervated spine located $<140 \mu \mathrm{m}$ laterally from the postsynaptic soma. Spines distal to their parent soma were preferentially innervated by cells on the ipsilateral side. Large spines $\left(>0.2 \mathrm{~mm}^{3}\right)$ tended to be innervated by cells on the ipsilateral side, while small spines $(<0.2$ $\mathrm{mm}^{3}$ ) tended to be innervated by cells on both sides. However, no cluster of neurons innervating the same dendritic branch was detected. The method described here is a valuable first step toward elucidating the basic microarchitecture of connectivity between neurons and synapses, and the stimulation of presynaptic cells that may induce nonlinear dendritic integration in the postsynaptic cell.

\section{Methods}

\section{Slice preparation}

Slices (350- $\mu \mathrm{m}$ thick) of motor cortex were prepared from 17 - to 20-day-old Sprague-Dawley rats in accordance with the procedure described by Kawaguchi et al., [43] using a cutting solution containing $120 \mathrm{mM}$ choline chloride, $3 \mathrm{mM} \mathrm{KCl}, 8 \mathrm{mM} \mathrm{MgCl} 2,1.25 \mathrm{mM} \mathrm{NaH}_{2} \mathrm{PO}_{4}$, $26 \mathrm{mM} \mathrm{NaHCO}_{3}$ and $25 \mathrm{mM}$ glucose. Slices were incubated at $32^{\circ} \mathrm{C}$ for $30 \mathrm{~min}$ and then stored in an incubation chamber at room temperature $\left(22^{\circ}-25^{\circ} \mathrm{C}\right)$ for at least $1 \mathrm{~h}$. Each slice was transferred to a recording chamber at room temperature. The extracellular solution contained $125 \mathrm{mM} \mathrm{NaCl}, 2.5 \mathrm{mM} \mathrm{KCl}, 2-3 \mathrm{mM}$ $\mathrm{CaCl}_{2}, 1 \mathrm{mM} \mathrm{MgCl}, 1.25 \mathrm{mM} \mathrm{NaH} \mathrm{PO}_{4}, 26 \mathrm{mM}$ $\mathrm{NaHCO}_{3}, 20 \mathrm{mM}$ glucose, $200 \mu \mathrm{M}$ Trolox (Aldrich, WI, USA), and $1.5 \mathrm{mM}$ CDNI-glutamate [20]. The extracellular solution (2-4 mL) was oxygenated and recirculated continuously. All experiments were approved by the animal experimentation committee of the Faculty of Medicine, University of Tokyo.

\section{Electrophysiology}

Patch-clamp electrodes (open-tip resistance, 4-8 M $\Omega$ ) were filled with a solution containing $135 \mathrm{mM}$ cesium gluconate, $4 \mathrm{mM} \mathrm{MgCl}_{2}, 10 \mathrm{mM}$ disodium phosphocreatine, $4 \mathrm{mM}$ Na-ATP, $0.4 \mathrm{mM}$ Na-GTP, $10 \mathrm{mM}$ HEPES-CsOH, $45 \mu \mathrm{M}$ Alexa Fluor 594 and $0.75 \mathrm{mM}$ Fluo-5F (pH 7.2, 293 mOsm). QX314 (5 mM) and D600 $(0.5 \mathrm{mM})$ were also included to minimize the occurrence of dendritic spikes and $\mathrm{Ca}^{2+}$ influx via voltagegated $\mathrm{Ca}^{2+}$ channels. In $\mathrm{Ca}^{2+}$ imaging of dendritic spines during 2pMAPG mapping, recordings were obtained from layer 5 pyramidal cells in the agranular area located $60 \pm 13 \mu \mathrm{m}$ [mean \pm standard deviation (SD), $n=18$ ] deep and $825 \pm 65$ (SD) from the pia. Series resistance was $17 \pm 7$ (SD) $\mathrm{M} \Omega$. The $\mathrm{Ca}^{2+}$ imaging regions were $47 \pm 23(\mathrm{SD}) \mu \mathrm{m}$ deep $(n=25)$. During $\mathrm{Ca}^{2+}$ imaging, the membrane potential was held at -30 $\mathrm{mV}$ to remove the $\mathrm{Mg}^{2+}$ block of NMDARs. The liquid junction potential was not corrected. In experiments to detect APs in layer 2/3 pyramidal neurons under the whole-cell current-clamp mode, the intracellular solution contained $138 \mathrm{mM}$ potassium gluconate, $4 \mathrm{mM}$ $\mathrm{MgCl}_{2}, 10 \mathrm{mM}$ disodium phosphocreatine, $50 \mu \mathrm{M}$ Alexa Fluor 594, $4 \mathrm{mM} \mathrm{Na-ATP,} 0.3 \mathrm{mM} \mathrm{Na-GTP}$ and 10 $\mathrm{mM}$ HEPES-KOH (pH 7.2, 297 mOsm). The mean resting potential of the cells was $-72 \pm 3(\mathrm{SD}) \mathrm{mV}(n=8)$. 
Data were low-pass filtered at $2 \mathrm{kHz}$, sampled at 5-10 $\mathrm{kHz}$, and recorded using FV1000-MPE software (Olympus, Tokyo, Japan).

Electrical stimulation was performed using a glass pipette filled with Alexa Fluor 594 dissolved in extracellular solution containing $2 \mathrm{mM} \mathrm{Ca}^{2+}$. Alexa Fluor 594 was used to visualize the position of the pipette and to keep it away from the dendrite. A current of 20-50 $\mu \mathrm{A}$ was applied for $0.1 \mathrm{~ms}$ per stimulation.

\section{Two-photon excitation imaging and uncaging of glutamate}

Experiments were performed using an upright microscope (BX61WI; Olympus) and an FV1000-MPE laserscanning microscope system. Since $\mathrm{Ca}^{2+}$ imaging required high spatial resolution and 2pMAPG mapping should be performed over a broad area, a water-immersion objective with a high-numerical-aperture (NA) and low-magnification configuration (XLUMPlanFI/IR 25x, NA of 1.05) was used. Two mode-locked femtosecondpulse Ti:sapphire lasers (MaiTai HP and MaiTai HP DeepSee; Spectra Physics, CA, USA) set at 720 and 830 $\mathrm{nm}$ were connected to the laser-scanning microscope via two independent scanheads (Figure 2). The laser emitted from the MaiTai HP was chirp compensated prior to entering the scanhead.

For 2pMAPG, the diameter of the 720-nm laser beam was adjusted to underfill the back aperture of the objective. This adjustment was achieved by using a motordriven stage (SGSP20-85; Sigma-Koki, Tokyo, Japan) to change the distance between the two convex lenses in the optical pathway prior to entering the scanhead (Figure 2). As a result, the effective NA was small and the focal volume was large. In addition, the laser intensity was increased to release much more caged glutamate and, therefore, to activate many more glutamate receptors near the focal volume than could be achieved at the diffraction limit [7]. This modification allowed effective induction of APs in cells near the focal volume.

In order to image dendritic spines at high resolution, the diameter of the 830-nm laser beam was adjusted to overfill the back aperture of the objective. The FWHM of the focal volume of the laser beam at $830 \mathrm{~nm}$ was estimated to be $0.41 \pm 0.01$ (SEM) $\mu \mathrm{m}$ laterally and 1.57 \pm 0.02 (SEM) $\mu \mathrm{m}$ axially $(n=10)$. The illumination time of the lasers was regulated by acoustic optical modulators (Figure 2). Fluorescence emitted from the specimen was separated using a 560-nm dichroic mirror (FF560; Semrock, NY, USA) and one of two barrier filters (FF01-510/84 [Semrock] or HQ 620/60 [Chroma Technology, VT, USA]), followed by detection with photomultiplier tubes in the green $(G)$ and red (R) fluorescence, respectively (Figure 2).
Images of neuronal structure were acquired by twodimensional scanning with the 830-nm laser at different depths and these images were stacked perpendicular to the image plane. Pixel lengths for imaging whole neurons and dendritic spines were $0.96 \mu \mathrm{m}$ and 0.08-0.16 $\mu \mathrm{m}$, respectively. In all figures with fluorescent images of whole neurons, the top of the image is closest to the pial surface. The locations of recorded cells and laminar borders were identified under trans-illumination of the 830-nm laser scanning with a low-magnification objective (MPlan N $5 \mathrm{x}$, NA of 0.1).

For 2 pMAPG mapping, 128 pixels $(16 \times 8$, spaced 31 $\mu \mathrm{m}$ apart) were scanned. Within each pixel, laser-mediated photolysis at $720 \mathrm{~nm}$ was performed consecutively at $3 \times 3$ points using lateral intervals of $6 \mu \mathrm{m}$ with a pulse-train duration of $9 \mathrm{~ms}$ (1 ms at each point) [7]. The mapping was performed at 3 different depths, each separated by $50 \mu \mathrm{m}$. Brain tissue scatters light, and the strength of scattering is described by the average length of the distance between scattering events $\left(l_{s}\right)$ [44]. To maintain constant laser power for photolysis $(\mathrm{P}=32-35 \mathrm{~mW})$ within the mapped plane at depth $z$ from the slice surface, the laser power was adjusted to $\mathrm{P} / \mathrm{e}^{-\mathrm{z} / \mathrm{ls}}$ before entering the tissue slice, with $l_{s}$ set to $80 \mu \mathrm{m}$. The focal plane was moved by regulating a piezo actuator (PI 721, Physik Instrumente, Karlsruhe, Germany) attached to the objective (Figure 2 and Additional File 1: Figure S1A). In contrast to our previous experiments of 2pMAPG mapping to detect EPSCs, [7] $\mathrm{Ca}^{2+}$ imaging required a long time interval between each 2pMAPG (470 ms versus $100 \mathrm{~ms}$ ) because $\mathrm{Ca}^{2+}$ transient decay $(>200 \mathrm{~ms}$ ) was much slower than EPSC decay ( $\sim 20 \mathrm{~ms})$. In addition, photobleaching of the fluorescence depended on the duration of imaging. Thus, the space between neighbouring 2pMAPG pixels was increased from $19 \mu \mathrm{m}$ to $31 \mu \mathrm{m}$ laterally and from $25-30 \mu \mathrm{m}$ to $50 \mu \mathrm{m}$ axially and the total number of 2 pMAPG mapping pixels was reduced from 3072-5120 to 384. In order to keep the number of AP-evoking pixels during this rough mapping similar to that in our prior report $(\sim 8)$, the focal volume for 2pMAPG was increased approximately threefold from the previous experiments [7].

\section{Data analysis}

Spine size was estimated as described previously [22] FWHM was measured for the heads of large, sphere-like spines (criterial spines) and then fitted to the FHWMdiameter curve, followed by estimation of the diameter and volume of the head. [22]. After that, the volumes of other spines were estimated based on total fluorescence intensity. $\mathrm{Ca}^{2+}$ transients that occurred in spines during the first or second imaging frame after stimulation and with amplitude larger than the mean of $G / R_{\text {base }}$ and 5 $\mathrm{CV}$ of $\mathrm{G} / \mathrm{R}_{\text {base }}$ were analyzed as described in the main 
text. FV1000-MPE software, IPLab (BD Biosciences, MD, USA) and our own software programs based on LabView (National Instruments, TX, USA) were used for image processing. Data are presented as means \pm SEM, unless stated otherwise. Error bars on graphs correspond to the SEM. Mann-Whitney $U$ test, Spearman's rank correlation, Student's paired $t$ test, and one-way ANOVA were used for statistical comparisons. A $P$ value of $<0.05$ was used as the criterion for a significant statistical difference.

\section{Additional material}

Additional file 1: Rapid axial movement driven by a piezo actuator.

The focal plane was moved by regulating a piezo actuator attached to the objective with dampers.

Additional file 2: Grouped $\mathrm{Ca}^{2+}$ transient-evoking pixels. If $\mathrm{Ca}^{2+}$ transients in a spine occurred in the imaging frames immediately after 2pMAPG at the green pixel and at least one of the red pixels, these pixels were referred to as grouped $\mathrm{Ca}^{2+}$ transient-evoking pixels.

Additional file 3: Correlation between the occurrence of $\mathrm{Ca}^{2+}$ transients and putative postsynaptic currents. If the laser intensity for 2 pMAPG was reduced, neither $\mathrm{Ca}^{2+}$ transients nor putative postsynaptic currents were evoked.

\section{Acknowledgements}

We thank C Miura and R Takizawa for technical assistance.

\section{Grants}

This work was supported by Scientific Research on Priority Areas-Elucidation of neural network function in the brain (No. 20021008 to MM) and for a Young Scientist (A: No. 19680020 to MM), and by Grants-in-Aids for a Specially Promoted Area (No. 2000009 to HK) from the Ministry of Education, Culture, Sports, Science and Technology (MEXT), Japan; by a Mitsubishi foundation grant to MM; and by National Institute of Health Grants GM65473 (to GCRE-D and HK) and GM53395 (GCRE-D).

\section{Author details}

'Laboratory of Structural Physiology, Center for Disease Biology and Integrative Medicine, Graduate School of Medicine, University of Tokyo, Tokyo, Japan. ${ }^{2}$ Center for NanoBio Integration, University of Tokyo, Tokyo, Japan. ${ }^{3}$ PRESTO, CREST, Japan Science and Technology Agency, Saitama, Japan. ${ }^{4}$ Current Address: Division of Brain Circuits, National Institute for Basic Biology, Okazaki, Japan. ${ }^{5}$ Department of Neuroscience, Mount Sinai School of Medicine, New York, NY 10029, USA.

\section{Authors' contributions}

MM conceived of the study, carried out the experiments, analyzed the data, and drafted the manuscript. GCRE-D synthesized CDNI-glutamate and helped to draft the manuscript. YK helped to perform the experiments. HK participated in the design of the study, provided resources and support for the experiments and helped to draft the manuscript. All authors read and approved the final manuscript.

\section{Competing interests}

The authors declare that they have no competing interests.

Received: 13 April 2010 Accepted: 7 July 2010

Published: 26 January 2011

\section{References}

1. Callaway EM, Katz LC: Photostimulation using caged glutamate reveals functional circuitry in living brain slices. Proc Natl Acad Sci USA 1993, 90(16):7661-7665.
2. Katz LC, Dalva MB: Scanning laser photostimulation: a new approach for analyzing brain circuits. J Neurosci Methods 1994, 54(2):205-218.

3. Dantzker JL, Callaway EM: Laminar sources of synaptic input to cortical inhibitory interneurons and pyramidal neurons. Nat Neurosci 2000, 3(7):701-707.

4. Schubert D, Staiger JF, Cho N, Kotter R, Zilles K, Luhmann HJ: Layer-specific intracolumnar and transcolumnar functional connectivity of layer $\mathrm{V}$ pyramidal cells in rat barrel cortex. J Neurosci 2001, 21(10):3580-3592.

5. Shepherd GMG, Svoboda K: Laminar and columnar organization of ascending excitatory projections to layer $2 / 3$ pyramidal neurons in rat barrel cortex. J Neurosci 2005, 25(24):5670-5679.

6. Nikolenko V, Poskanzer KE, Yuste R: Two-photon photostimulation and imaging of neural circuits. Nat Methods 2007, 4(11):943-950.

7. Matsuzaki M, Ellis-Davies GCR, Kasai H: Three-dimensional mapping of unitary synaptic connections by two-photon macro photolysis of caged glutamate. J Neurophysiol 2008, 99(3):1535-1544.

8. Matsuzaki M: Factors critical for the plasticity of dendritic spines and memory storage. Neurosci Res 2007, 57(1):1-9.

9. Matsuzaki M, Ellis-Davies GCR, Nemoto T, Miyashita Y, lino M, Kasai H: Dendritic spine geometry is critical for AMPA receptor expression in hippocampal CA1 pyramidal neurons. Nat Neurosci 2001, 4(11):1086-1092.

10. Smith MA, Ellis-Davies GCR, Magee JC: Mechanism of the distancedependent scaling of Schaffer collateral synapses in rat CA1 pyramidal neurons. J Physiol 2003, 548(Pt 1):245-258.

11. Beique JC, Lin DT, Kang MG, Aizawa H, Takamiya K, Huganir RL: Synapsespecific regulation of AMPA receptor function by PSD-95. Proc Natl Acad Sci USA 2006, 103(51):19535-19540.

12. Larkum ME, Nevian T: Synaptic clustering by dendritic signalling mechanisms. Curr Opin Neurobiol 2008, 18(3):321-331.

13. London M, Hausser M: Dendritic computation. Annu Rev Neurosci 2005, 28:503-32.

14. Losonczy A, Magee JC: Integrative properties of radial oblique dendrites in hippocampal CA1 pyramidal neurons. Neuron 2006, 50(2):291-307.

15. Schiller J, Major G, Koester HJ, Schiller Y: NMDA spikes in basal dendrites of cortical pyramidal neurons. Nature 2000, 404(6775):285-289.

16. Markram H, Lubke J, Frotscher M, Roth A, Sakmann B: Physiology and anatomy of synaptic connections between thick tufted pyramidal neurones in the developing rat neocortex. J Physiol 1997, 500(Pt 2):409-440.

17. Feldmeyer D, Lubke J, Silver RA, Sakmann B: Synaptic connections between layer 4 spiny neurone-layer $2 / 3$ pyramidal cell pairs in juvenile rat barrel cortex: physiology and anatomy of interlaminar signalling within a cortical column. J Physiol 2002, 538(Pt 3):803-822.

18. Koester HJ, Johnston D: Target cell-dependent normalization of transmitter release at neocortical synapses. Science 2005, 308(5723):863-866

19. Morishima M, Kawaquchi Y: Recurrent connection patterns of corticostriatal pyramidal cells in frontal cortex. J Neurosci 2006, 26(16):4394-4405.

20. Ellis-Davies GCR, Matsuzaki M, Paukert M, Kasai H, Bergles DE: 4Carboxymethoxy-5,7-dinitroindolinyl-Glu: an improved caged glutamate for expeditious ultraviolet and two-photon photolysis in brain slices. J Neurosci 2007, 27(25):6601-6604.

21. Ballesteros-Yanez I, avides-Piccione R, Elston GN, Yuste R, DeFelipe J: Density and morphology of dendritic spines in mouse neocortex. Neuroscience 2006, 138(2):403-409.

22. Noguchi J, Matsuzaki M, Ellis-Davies GCR, Kasai H: Spine-neck geometry determines NMDA receptor-dependent $\mathrm{Ca} 2+$ signaling in dendrites. Neuron 2005, 46(4):609-622.

23. Yasumatsu N, Matsuzaki M, Miyazaki T, Noguchi J, Kasai H: Principles of long-term dynamics of dendritic spines. J Neurosci 2008, 28(50):13592-13608.

24. Harris KM, Stevens JK: Dendritic spines of CA 1 pyramidal cells in the rat hippocampus: serial electron microscopy with reference to their biophysical characteristics. J Neurosci 1989, 9(8):2982-2997.

25. Murthy VN, Schikorski T, Stevens CF, Zhu Y: Inactivity produces increases in neurotransmitter release and synapse size. Neuron 2001, 32(4):673-682

26. Holmgren C, Harkany $T$, Svennenfors B, Zilberter Y: Pyramidal cell communication within local networks in layer $2 / 3$ of rat neocortex. J Physiol 2003, 551(Pt 1):139-153. 
27. Lubke J, Roth A, Feldmeyer D, Sakmann B: Morphometric analysis of the columnar innervation domain of neurons connecting layer 4 and layer 2/3 of juvenile rat barrel cortex. Cereb Cortex 2003, 13(10):1051-1063.

28. Kalisman N, Silberberg G, Markram H: The neocortical microcircuit as a tabula rasa. Proc Natl Acad Sci USA 2005, 102(3):880-885.

29. Shepherd GMG, Stepanyants A, Bureau I, Chklovskii D, Svoboda K: Geometric and functional organization of cortical circuits. Nat Neurosci 2005, 8(6):782-790.

30. Stepanyants A, Chklovskii DB: Neurogeometry and potential synaptic connectivity. Trends Neurosci 2005, 28(7):387-394.

31. Mel BW, Ruderman DL, Archie KA: Translation-invariant orientation tuning in visual "complex" cells could derive from intradendritic computations. J Neurosci 1998, 18(11):4325-4334.

32. Poirazi P, Brannon T, Mel BW: Pyramidal neuron as two-layer neural network. Neuron 2003, 37(6):989-999.

33. Polsky A, Mel BW, Schiller J: Computational subunits in thin dendrites of pyramidal cells. Nat Neurosci 2004, 7(6):621-627.

34. Bollmann JH, Engert F: Subcellular topography of visually driven dendritic activity in the vertebrate visual system. Neuron 2009, 61(6):895-905.

35. Yoshimura Y, Callaway EM: Fine-scale specificity of cortical networks depends on inhibitory cell type and connectivity. Nat Neurosci 2005, 8(11):1552-1559.

36. Kampa BM, Letzkus JJ, Stuart GJ: Cortical feed-forward networks for binding different streams of sensory information. Nat Neurosci 2006, 9(12):1472-1473.

37. Otsuka T, Kawaguchi Y: Firing-pattern-dependent specificity of cortical excitatory feed-forward subnetworks. J Neurosci 2008, 28(44):11186-11195.

38. Yu YC, Bultje RS, Wang X, Shi SH: Specific synapses develop preferentially among sister excitatory neurons in the neocortex. Nature 2009, 458(7237):501-504

39. Brown $S P$, Hestrin $S$ : Intracortical circuits of pyramidal neurons reflect their long-range axonal targets. Nature 2009, 457(7233):1133-1136.

40. Gobel W, Helmchen F: New angles on neuronal dendrites in vivo. J Neurophysiol 2007, 98(6):3770-3779.

41. Fino E, Araya R, Peterka DS, Salierno M, Etchenique R, Yuste R: RuBiGlutamate: Two-Photon and Visible-Light Photoactivation of Neurons and Dendritic spines. Front Neural Circuits 2009, 3:2.

42. Rickgauer JP, Tank DW: Two-photon excitation of channelrhodopsin-2 at saturation. Proc Natl Acad Sci USA 2009, 106(35):15025-15030

43. Kawaguchi $Y$, Wilson CJ, Emson PC: Intracellular recording of identified neostriatal patch and matrix spiny cells in a slice preparation preserving cortical inputs. J Neurophysiol 1989, 62(5):1052-1068.

44. Helmchen F, Denk W: Deep tissue two-photon microscopy. Nat Methods 2005, 2(12):932-940.

doi:10.1186/2042-1001-1-2

Cite this article as: Matsuzaki et al.: Simultaneous two-photon activation of presynaptic cells and calcium imaging in postsynaptic dendritic spines. Neural Systems \& Circuits 2011 1:2.

\section{Submit your next manuscript to BioMed Central and take full advantage of:}

- Convenient online submission

- Thorough peer review

- No space constraints or color figure charges

- Immediate publication on acceptance

- Inclusion in PubMed, CAS, Scopus and Google Scholar

- Research which is freely available for redistribution

Submit your manuscript at www.biomedcentral.com/submit
CioMed Central 